\title{
Percepção de adolescentes grávidas sobre a gestação precoce
}

\author{
Perception of pregnant adolescents on early gesture
}

\section{Percepción de adolescentes embarazados en el gesto temprano}

Camila de Assunção Teixeira Campos ${ }^{1}$, Jaciara Oliveira Corrêa ${ }^{1}$, Nádile Juliane Costa de Castro², Shirley Aviz de Miranda ${ }^{1}$.

\section{RESUMO}

Objetivo: Investigar a percepção de adolescentes grávidas sobre gestação precoce. Método: A abordagem utilizada foi qualitativa de caráter exploratório, avaliada por meio de dados obtidos a partir de pesquisa de campo em uma unidade de Estratégia Saúde da Família (ESF) no bairro da Pratinha, Distrito Administrativo de Saúde do Bengui (DABEN), município Belém/PA, no ano de 2017, após aprovação no comitê de ética em pesquisa. A amostra foi composta por onze adolescentes grávidas com faixa etária entre 15 a 19 anos por meio de entrevista semiestruturada. Resultado: $O$ estudo resultou em três categorias: Percepções de adolescentes grávidas sobre ser mãe jovem, mudanças no cotidiano, e preconceitos e dificuldades em ser mãe adolescente. Os resultados apontaram que dentre as onze entrevistadas, a maioria se declarou parda e com ensino médio incompleto. Conclusão: A gravidez precoce não planejada impactou direta e negativamente a vida das adolescents sendo relativas ao défict de informação e prevenção. É necessário ampliar o estudo para compreensão da escuta sensível sobre o tema e demais repercussões para o planejamento familiar.

Palavras-chave: Gravidez na adolescência, Família, Saúde Pública.

\begin{abstract}
Objective: To investigate the perception of pregnant adolescents about precocious pregnancy. Method: The qualitative approach was an exploratory one, evaluated by means of data obtained from field research in a Family Health Strategy (ESF) unit in Pratinha neighborhood, Bengui Health Administrative District (DABEN), municipality Belém / PA, in 2017, after approval by the research ethics committee. The sample consisted of eleven pregnant adolescents aged between 15 and 19 years through a semi-structured interview. Results: The study resulted in three categories: Perceptions of pregnant adolescents about being a young mother, change in daily life, and prejudices and difficulties in being a teenage mother. The results indicated that among the eleven interviewed, the majority declared themselves to be brown with incomplete secondary education. Conclusion: Unplanned early pregnancy directly and negatively impacted the lives of adolescents, being related to the information deficit and prevention. It is necessary to expand the study to understand the sensitive listening on the theme and other repercussions for family planning.
\end{abstract}

Key words: Adolescent pregnancy, Family, Public Health.

${ }^{1}$ Faculdade Metropolitana da Amazônia (FAMAZ), Belém-PA. *E-mail: camilaatcampos@hotmail.com

${ }^{2}$ Núcleo de Altos Estudos Amazônicos (NAEA), Universidade Federal do Pará (UFPA). 


\section{RESUMEN}

Objetivo: Investigar la percepción de adolescentes embarazadas sobre gestación precoz. Método: El abordaje utilizado fue cualitativo de carácter exploratorio, evaluado por medio de datos obtenidos a partir de investigación de campo en una unidad de Estrategia Salud de la Familia (ESF) en el barrio de Pratinha, Distrito Administrativo de Salud del Bengui (DABEN), municipio Belém / PA, en el año 2017, tras la aprobación en el comité de ética en investigación. La muestra fue compuesta por once adolescentes embarazadas con rango de edad entre 15 a 19 años por medio de una entrevista semiestructurada. Resultado: El estudio resultó en tres categorías: Percepciones de adolescentes embarazadas sobre ser madre joven, el cambio en el cotidiano, y los prejuicios y dificultades en ser madre adolescente. Los resultados apuntaron que entre las once entrevistadas, la mayoría se declaró parda y con enseñanza media incompleta. Conclusión: El embarazo precoz no planificado impactó directa y negativamente la vida de las adolescentes con respecto al déficit de información y prevención. Es necesario ampliar el estudio para comprender la escucha sensible sobre el tema y demás repercusiones para la planificación familiar.

Palabras clave: Embarazo en la adolescencia, Familia, Salud Pública.

\section{INTRODUÇÃO}

A gravidez na adolescência é uma problemática que envolve vários campos de estudo além da saúde, inserido em uma faixa etária oportunamente bem definida nas políticas de saúde e sociais. Para direcionamento das políticas de saúde a Organização Mundial da Saúde (OMS) define a adolescência como um período onde ocorre a passagem da infância para a vida adulta (SILVA MHD, 2016). É um período que perpassa por várias mudanças biológicas, psicológicas e sociais que estão relacionadas ao crescimento físico, maturação sexual, aquisição da capacidade de reprodução e o amadurecimento adulto inserida no contexto social (NASCIMENTO GM et al., 2011). A gestação precoce ocorre entre adolescentes de 10 a 14 anos de idade. A concepção de que a gravidez na adolescência constitui grande risco, tanto para a saúde das mulheres quanto para a das crianças recém-nascidas, também tem contribuído para que seja qualificada como precoce e como problema de saúde pública (MELO JS et al., 2017). O número de nascidos vivos por residência com mãe em idade entre 10 a 14 anos no Brasil no período de 2010 a 2016 foi de 190.138 . Na região Norte foram 35.398 nascimentos (DATASUS, 2018).

Há diversos determinantes que estão relacionadas diretamente à saúde dos adolescentes, como a concepção familiar e o nível de escolaridade dos jovens. Estes tendem a intervir em numerosos aspectos relativos à sua própria saúde, destacando as vulnerabilidades as quais estão sujeitos nessa fase de desenvolvimento e os riscos de adquirir Infecções Sexualmente Transmissíveis (ISTs). Ademais, além da gravidez precoce indesejada e não planejada está a fragilidade de ações educativas sobre educação sexual, planejamento reprodutivo, e de condições socioeconômicas e culturais (ACHARYA D et al., 2010).

Estas posturas instituem condições para que estas jovens sejam capazes de lidar com suas próprias decisões, e elencando atitudes positivas para lidar com papel do autocuidado (RIBEIRO VCDS et al., 2016).

É necessário refletir sobre algumas questões que estão fortemente associadas a problemática da gravidez na adolescência, destacando-se entre elas: a sexualidade dos adolescentes, educação sexual, uso de métodos contraceptivos, infecções sexualmente transmissíveis, a AIDS, o abandono escolar e a violência relacionada ao abuso sexual (SANTOS BPF, 2015).

Em contrapartida situações regionais geram atenção, como no caso da região Norte e especialmente no Pará, por suas peculiaridades geográficas (ANJOS JCS et al., 2014).

Nesse sentido, visando contribuir com o conhecimento acerca da percepção de adolescentes grávidas, realizou-se um estudo norteado pelo seguinte questionamento: Qual a percepção de grávidas adolescentes sobre a gestação precoce? Este direcionamento veio por meio de vivências acadêmicas nas práticas supervisionadas na Estratégia Saúde da Família (ESF), onde foi observado um índice elevado de adolescentes grávidas. 
Ao revelar esses fatos, o objetivo geral desse estudo foi conhecer a percepção de adolescentes grávidas sobre a gestação precoce. É um estudo que visa qualificar o atendimento das adolescentes grávidas, contribuindo para ações voltadas para a saúde da adolescente.

\section{MÉTODOS}

Estudo com abordagem qualitativa, exploratório desenvolvido por meio de um estudo de caso único, (CRESWELL JW, 2013; YIN RK, 2016). Foi realizado em uma ESF, localizada no bairro da Pratinha, Distrito Administrativo de Saúde do Bengui (DABEN), no município de Belém/PA. A referente estratégia saúde da família faz cobertura para em torno de 8.000 pessoas da região, e é composta por duas equipes de saúde, com dois médicos, dois enfermeiros, dois técnicos e quinze agentes comunitários de saúde (ACS).

A população de estudo foi composta por onze adolescentes grávidas, dentro da faixa etária de 15 a 19 anos. Foram excluídas do estudo as adolescentes que não conseguiam se expressar oralmente, que não estavam grávidas, que não faziam parte do universo estudado, desacompanhadas do responsável, e/ou que não residem na comunidade ou ainda as que não aceitaram a participar da pesquisa.

As adolescentes foram convidadas a participar do estudo, após serem dadas informações e esclarecimentos sobre os objetivos e importância do estudo. Mediante o consentimento, foi apresentado $o$ Termo de Consentimento Livre Esclarecido (TCLE), o qual foi assinado pelos responsáveis legais das adolescentes e o termo de Assentimento (TA), onde foi solicitada a leitura para posterior assinatura em caso de concordância com os termos expostos. O TA é um documento que visa esclarecer, assim como dar anuência sobre a pesquisa a menores de 18 anos, sendo ainda assim obrigatório a assinatura do TCLE pelos responsáveis legais.

Como condição das questões éticas foram utilizados codinomes para cada uma das participantes, buscando preservar a identidade das adolescentes nesta pesquisa, utilizando nomes populares de flores da flora brasileira e estrangeira, tais como: Bromélia, Flor de Alteia, Anis, Girassol, Jasmim, Camomila, Hortência, Flor de Acácia, Flor de Lotus, Anêmona e Dália. A coleta dos dados foi feita na unidade de saúde, e realizada por meio de entrevista semiestruturada. A análise dos dados foi realizada a partir da metodologia de análise de conteúdo e suas etapas. As entrevistas foram gravadas in loco onde as adolescentes realizaram o prénatal, onde, posteriormente, os depoimentos foram ouvidos e transcritos integralmente, analisados e agrupados compondo unidades temáticas.

O presente estudo respeitou os princípios éticos e legais da pesquisa, conforme o emanado pela Resolução n. 466/12 do Conselho Nacional I de Saúde - CNS (BRASIL, 2012). A pesquisa foi autorizada sob o número do CAAE: 73811317.0.0000.5701, resguardando deste modo os princípios éticos de anonimato, não maleficência, beneficência e justiça.

\section{RESULTADOS E DISCUSSÃO}

Fizeram parte do estudo 11 (100\%) adolescentes grávidas com faixa etária entre 15 a 19 anos. Em referência ao perfil: do total de participantes apenas duas $(2 / 11-18,18 \%)$ apresentaram idade de 15 anos, sete $(7 / 11-63,63 \%)$ delas apresentaram 16 anos, uma (1/11 - 9,09\%) com 18 e uma (1/11) com 19 . Das 11 grávidas, $9(9 / 11-81,81 \%)$ se declararam pardas, uma $(1 / 11-9,9 \%)$ branca, e uma $(1 / 11-9,9 \%)$ se considerou negra.

Quanto ao nível de escolaridade, das 11 adolescentes, 7 (7/11 - 63,63\%) apresentaram o ensino médio incompleto, $3(3 / 11-27,27 \%)$ o ensino fundamental incompleto e apenas uma (1/11 - 9,9\%) havia concluído o ensino médio. No tocante ao estado civil das entrevistadas, dentre as denominações mencionadas solteiras, união estável e casada, das adolescents, 10 (10/11 - 90,90\%) relataram união estável e uma referiu ser casada. Das grávidas, $8(8 / 11-72,72 \%)$ referiram não estudar mais e três $(3 / 11-27,27 \%)$ ainda estudam. 
Tendo por base os relatos coletados e o agrupamento das falas em torno de eixos temáticos, surgiram três categorias com os seguintes títulos: "Percepções de adolescentes grávidas sobre ser mãe jovem"; "Mudanças no cotidiano" e "Preconceitos, dificuldades em ser mãe adolescente".

\section{Percepções de adolescentes grávidas sobre ser mãe jovem}

A gravidez na adolescência é multicausal, assim as causas que levam as adolescentes a engravidarem tão precocemente podem estar relacionados a fatores familiares, sociais, biológicos, psicológicos e métodos contraceptivos mal utilizados pelos adolescentes (DUARTE JVC, 2011). Baseado nestas assertivas, e referente às percepções das adolescentes grávidas, foi percebido em todos os relatos que a gravidez não foi algo planejado e que impactou diretamente suas vidas. As entrevistas identificaram como condicionante desta situação: a falta de informação e de prevenção como os principais motivos apontados pelas adolescentes para a gravidez não planejada:

“Não, tenho 15 anos e não passava pela minha cabeça, não sabia, nem os riscos” (Alteia)

"Não, não me preveni" (Anis)

"Não foi planejada, foi um descuido" (Girassol).

O acesso a informação hodiernamente apesar dos avanços tecnológicos, ainda tem sido um dos grandes motivos que afetam as escolhas que levam a gravidez precoce. Guedes JS (2015) afirma que é fato que tanto o Sistema Único de Saúde (SUS) e outros mecanismos de acesso a informação tem apresentando alternativas para estimular os adolescentes a prática do sexo seguro, entretanto, estes resultados apontam realidades que se distanciam dos objetivos propostos. Ainda, segundo Guedes JS (2015) existe uma lacuna entre o conhecimento e o uso dos contraceptivos, revelando que apesar de terem clareza do risco de engravidar por meio da prática sexual sem o uso de medidas preventivas, as adolescentes optam por "correr o risco" com a relação sexual desprotegida.

Há outros condicionantes que se aplicam nesse processo da gravidez que de acordo com Paes e Abraão (2014) é percebido quando o emocional das adolescentes fica abalado e a gravidez é vivida como um momento de renúncias. No âmbito dos sentimentos vivenciados pelas mulheres no momento da descoberta da gravidez, percebe-se que o sentimento de tristeza, ansiedade e preocupação predominaram nos registros entre as adolescentes:

"Não queria por que eu tenho outro filho novo, fiquei triste, sei lá um sentimento de tristeza" (Jasmim)

"Me senti meio desanimada, por que não foi planejada do jeito que queria, fiquei triste" (Camomila)

"No começo foi muito difícil não queria aceitar, pensei até em aborto não vou mentir, mas depois fiquei muito feliz" (Hortência).

Por estes delineamentos conforme Rodrigues FRDA et al., (2009) o surgimento da gravidez acarreta momentos de tristeza, medos e incertezas devido à pressão social e familiar que é submetida. Há conflitos internos pela interrupção do processo socialmente aceito de adolescer e pela antecipação da identidade adulta. Questões psicológicas são bem evidentes quando de situações não planejadas, que pedem mudanças de hábitos e responsabilidades. Advém citar que os adolescentes, no momento que descobrem a gravidez, tendem a fugir da realidade, negando, rejeitando e buscando outros meios para impedir sua continuidade.

Nestes termos é que pensamentos quanto ao aborto ocorrem como demonstrado na fala anterior, e são vários os motivos elencados conforme cita Soares PDF et al. (2016) para justificar tal sentimento demedo, em virtude de não ter o apoio do parceiro, não aceitação/rejeição da gravidez e desespero. No entanto, é percebido que há também sentimentos positivos frente a situação:

"Ah me sinto feliz, alegre, queria ser mãe..." (Acácia). 


\section{"Não sei nem te dizer, muito preocupada" (Anis).}

São sentimentos inerentes ao ser humano que representam o medo, arrependimentos, alegria e aceitação por vezes relativos as mudanças corporais e os afetos empregados pela condição fisiológica. Ademais, é notório que nem sempre a maternidade na adolescência é encarada como uma desvantagem, mas sim como uma emancipação e até mesmo como um amadurecimento sexual e psicológico (EDUARDO KGT et al., 2005).Nesse sentido, Vasconcelos et al., (2010) descreve bem essa condição como uma sensação prazerosa sentida com a descoberta da gravidez como um momento repleto de felicidade e satisfação:

"Me sinto muito feliz, já quero que passe esses 9 meses pra cuidar da minha criança” (Bromélia).

"Muito feliz, mas no começo fiquei com medo de não saber lidar com a situação" (Flor de Lotus).

"Me sinto bem né, eu queria estudar, mas engravidei aí tive que parar, mas agora tô feliz!" (Camomila).

A maternidade concretiza-se como geradora de responsabilidade e desafios, ao mesmo tempo em que é promotora de um amadurecimento pessoal, social e emocional (SANTOS CC et al., 2014). Entretanto, outras entrevistadas narraram preocupação, medo de não saber lidar com a situação, o que repercutiu no sentimento de tristeza relativo a possibilidade ter que abandonar os estudos. São situações em que Moreira TMM et al., (2008) constatou que a grande maioria é despreparada física, psicológica, social e economicamente para exercer o novo papel materno.

A gravidez na adolescência é representada pelas adolescentes do estudo como uma condição nova e de progressão social, o que é representada pela nova posição de mãe ao invés de filha, o que traz uma carga de atribuições que podem revelar despreparo frente a tal situação (QUEIROZ MVO et al., 2010). No entanto, como dinâmica da vida e como resultado das escolhas, a maioria apresentou-se positiva quanto ao andamento da gravidez.

Nesse seguimento, foi possível verificar na fala das entrevistadas sentimentos positivos e negativos que a maternidade trouxe para sua vida. De uma maneira geral revelaram que ser mãe é amar, cuidar, amadurecer. Entretanto outras das adolescentes disseram que ser mãe adolescente é muito difícil, não souberam explicar de fato o que é a maternidade, mostraram-se bastante inseguras e com sentimento de preocupação:

"Pra mim ser mãe é cuidar, amar, acho que é amadurecer" (Anêmona).

"Um pouco difícil por que ser mãe é muito complicado ainda mais numa fase de adolescência, ainda não sei muita coisa, ainda não conheço nada" (Camomila).

Do ponto de vista das expectativas sociais e responsabilidades a serem assumidas pela mãe adolescente, e de como isso pode ser visto de maneira qualitativa, o nascimento do filho poderia ser considerado um desencadeador da transição da adolescência para vida adulta (SANTOS NLB, GUIMARAES DA, GAMA CAP; 2016).

Para Guedes JS (2015) a insegurança e o medo das situações novas que se apresentam em relação ao recém-nascido devem ser entendidos como um apelo, um pedido de ajuda do suporte de algum familiar.

\section{Mudanças no cotidiano}

O cotidiano é de fato o mais modificado pela condição da gravidez precoce e não planejada, e muda a vida das adolescentes depois de sua descoberta. Como aponta Santos BPF e Medeiros RER (2015) a gravidez precoce leva a impossibilidade de completar a função da adolescência, antecipando escolhas e abreviando experiências como abandono escolar, menor chance de qualificação e oportunidade de inserção no mercado de trabalho, dificuldade na implementação de outros projetos de vida, entre outros. Além do que, a gestação precoce pode trazer desvantagens à trajetória educacional da gestante, contribuindo para a evasão escolar e dificultando o retorno à escola e ao Mercado de trabalho (TABORDA JA et al., 2014).

"Ah muitas coisas, tudo... meu jeito, trabalho, parei de trabalhar com a minha tia, comecei a morar junto com meu marido" (Girassol). 
"Quase tudo, o dia a dia, ficou difícil de estudar, pois passava muito mal, deixei de fazer muitas coisas" (Flor de Lotus).

A dinâmica da vida dessas adolescentes se modificou pela condição fisiológica inerente a condição da gravidez, porém há situações relativas as questões socioeconômicas, familiares e educacionais. Em tese, a rotina destas jovens foi afetada ocasionando mudanças repentinas e não planejadas, por certo, a condição de vida de casados se distancia das rotinas da união que era de relacionamentos de namorados. Isso mostra que as mesmas não estão preparadas para encarar essa construção familiar que envolve organização de infraestrutura de lar:

"Bastante coisa, a vida de casado que antes era só namorada, responsabilidade" (Anis).

"Vim morar com meu marido que antes morava com minha tia, aí me casei e fiquei com ele agora" (Dália).

A gravidez pode, de fato, gerar a constituição de um novo núcleo familiar. O núcleo familiar induz novas relações parentais, novas conjunturas de valores, assim como da divisão de tarefas, deveres e fazeres. Mas o que se percebe, no entanto, e que a vinda de um filho também parece motivar a união física do jovem casal, representando uma via de ingresso no mundo adulto para os jovens (DIAS ACG et al., 2011). Há uma pressão social estabelecida para o vínculo conjugal, o que faz com que haja muitas vezes aceitação da união não apenas por acreditarem no relacionamento, mas pelo receio de criar o filho sem pai. Estas reações são referentes a família e as dificuldades financeiras para cuidar da criança sozinhas (SANTOS BPF e MEDEIROS RER, 2015). Não obstante a isso, ao questionar sobre a reação da paternidade no momento da descoberta da gravidez, segundo as falas das adolescentes, observou-se que alguns pais apresentaram no primeiro momento sentimentos de felicidade:

"Ele se assustou, mas depois aceitou, ficou do meu lado e muito feliz" (Bromélia).

"Ele ficou muito contente, ficou feliz e gostou da ideia de ser pai" (Flor de Lotus).

É premente que a paternidade seja estimulada em todos os momentos da gravidez, desde a notícia sobre a gestação e em todas as suas fases, afim de que o processo de paternidade se efetive naturalmente, fortalecendo os vínculos, cuidando e apoiando a gestante e seu filho. (BORDIGNON SS et al., 2013). Segundo Braga LP et (2015) a vida do homem muda ao tornar-se pai, uma vez que assume novas responsabilidades e faz renúncias a comportamentos típicos da juventude e tornam-se assim adulto. Muitos querem provar que são capazes de cuidar de seus filhos e observa-se a falta de jeito, as falhas, erros e omissões. No entanto, foi revelado que a princípio o parceiro quando recebeu a notícia da gravidez ficou feliz, em seguida a abandonou:

"Primeiro ele me disse que estava muito feliz, aí quando passou uns dias ele me abandonou, falou que a criança não era dele" (Camomila).

Quando da clareza das responsabilidades a serem aceitas como responsável daquela criança, este aceita a condição de mantenedor das necessidades afetivas, econômicas e educacionais, o que condiciona sentimentos de conflitos, pois são um conjunto de responsabilidades e que nem todo pai biológico está apto a aceitar, muitas vezes ficando isoladas a questões financeiras. Para Dias ACG e Patias NP (2013) segundo algumas convenções culturais, ser pai precocemente pode trazer preocupação e resistência ao meio social, já que a adolescência geralmente é compreendida como um período de formação tanto biológica quanto psicológica. Em relação ao o abandono do parceiro, a ausência dos companheiros é um fator estressante para a gestante, e para as futuras mães solteiras, que acabam por assumir solitariamente, a responsabilidade pelo filho (MIURA OP, TARDIVO LSLPC, BARRIENTOS MSB, 2018).

\section{Preconceitos e dificuldades em ser mãe adolescente}

Diversos preconceitos foram relatados pelas adolescentes tanto de familiares quanto de amigos. Em se tratando de sentimentos da família no momento da descoberta da gravidez, nesse estudo foi percebida na 
fala das participantes a família como contraria a gravidez e não apoiadora. Para a família a gravidez na adolescência é de difícil aceitação e provoca conflitos familiares que se tornam fontes de problemas para as adolescentes. Na fala das jovens podemos observar que a família cria expectativas sociais para a adolescente "aproveitar a vida, concluir os estudos, explorar o mundo deixando a gravidez em segundo plano" são sentimentos positivos esperados pelos familiares:

"Sim, eles falaram que era pra mim estudar, que eu era nova, que não era pra mim ter engravidado cedo" (Jasmim).

"Sim, principalmente minha família, meu pai ficou de mal comigo dias, muitos me brigavam, me chamavam de doida por ser adolescente" (Hortência).

Para Moreira IC (2010), na concepção da adolescente, o suporte familiar recebido durante a gravidez pode ser composto por ajuda financeira, explicações e conselhos. Entende-se que a família assume um papel particularmente importante ao fornecer suporte, que se reflete não apenas no grau de ligação social familiar, mas também, no apoio ao acolher o casal e aconselhar quanto a cuidados que devem ter durante a gestação (SANTOS CC et al., 2014). Independente deste apoioapontou-se dificuldades financeiras e abandono do parceiro:

"Não, graças a Deus tenho uma família maravilhosa que me ajuda muito" (Alteia).

"Sim, dificuldade financeira, pois meus pais não têm muito dinheiro e meu namorado me deixou tô preocupada com algumas coisas, mas creio que tudo vai dar certo, já tá dando" (Flor de Lotus).

A falta de apoio ou abandono por parte do parceiro causa a interrupção do processo normal do desenvolvimento psico-afetivo-social. Nestes casos, sofrem críticas de familiares, seja pelas pressões sociais envolvidas, seja por problemas financeiros (ALVES RD et al., 2016). É, portanto um processo continuo de atenção e cuidados, envolvendo a busca destes inclusive pelos programas como o pré-natal:

"Não, logo iniciei quando descobri a gravidez" (Anis).

"Não, descobri logo no início e minha mãe sempre vem comigo nas consultas" (Alteia).

A participação das adolescentes nesse programa é considerada uma experiência válida, principalmente no que se refere a esclarecimento de dúvidas sobre a gestação por serem mães precoces. Ademais, não somente a adolescente é envolvida nesse programa, toda a família poderá participar indiretamente, afetando positivamente o percurso da gestação. Por certo, a assistência pré-natal tem como principal objetivo acolher a mulher desde o início da gravidez. Sua adesão influencia na gestação, e a consulta pré-natal está relacionada à qualidade da assistência que é oferecida pelos serviços de profissionais da saúde, essencial para reduzir os altos índices de mortalidade materna e perinatal na população brasileira. Logo, para a boa qualidade do pré-natal está implícita valorização de todos esses aspectos, permitindo integração no conjunto das ações oferecidas pelos serviços de saúde (DAVIM BRM e DAVIM CMV, 2016).

Há outros fatos a serem destacados quando a gravidez ocorre em adolescentes muito jovens e de forma inesperada, as mesmas tentam negar o fato de forma consciente ou inconscientemente escondendo dos pais, procurando tardiamente os serviços de saúde para o acompanhamento pré-natal (DAVIM BRM e DAVIM CMV, 2016). São condições percebidas em muitos relatos da rede de atenção do SUS e é uma realidade também encontrada neste estudo:

"Sim, pois escondi a gravidez por 3 meses, pois estava com medo dos meus pais e inicie um pouco tarde" (Girassol).

"Sim, pois escondi a gravidez ate 3 meses e só depois que iniciei" (Bromélia).

A revelação da gravidez gera conflitos familiares em relação à aceitação por serem adolescentes. Sabendo disso, as participantes justificaram que esse sentimento de medo à descoberta dos pais, foi uma das dificuldades que levou a iniciarem o pré-natal tardio, pois esconderam a gravidez até certo mês de gestação. São projeções dos medos que vieram com a escolha errada do não planejamento e/ou proteção para uma 
gravidez precoce, e que deve ser percebida o quanto antes pela equipe de saúde para que as ações para a promoção de uma gravidez saudável sejam alcançadas, evitando transtornos psicossociais e biológicos.

\section{CONSIDERAÇÕES FINAIS}

Considerando o quadro social das jovens associado às abordagens realizadas pelo estudo foi possível concluir que a percepção das adolescentes grávidas sobre ser mãe jovem foi de que suas vidas sofreram impactos importantes após a gravidez, apontando a falta de informação e de prevenção como os principais motivos para uma gravidez não planejada. Foi evidenciada várias sensações e sentimentos como: tristeza, ansiedade, preocupação e alegria. Outrossim é premente a necessidade de fortalecimento da Política Nacional de Saúde dos Adolescentes no âmbito da atenção básica em saúde, assim como o estreitamento das relações entre saúde educação, por meio do programa Saúde na Escola (PSE), na perspectiva de se possibilitar diálogos e se impactar nos índices de gravidez inoportuna.

\section{REFERÊNCIAS}

1. ACHARYA D, et al. Factors associated with teenage pregnancy in South Asia: a systematic review. Health Science Journal, 2010, 4: 3-14.

2. ALVES RD, et al. Dificuldades enfrentadas por adolescentes no período gestacional. Temas em Saúde, 2016; $16(2): 2447-2131$.

3. ANJOS JCS, et al. Perfil epidemiológico das gestantes atendidas em um cento de referência em pré-natal de alto risco. Revista Paraense de Medicina.2014, 28: p. 6.

4. BARDIN L. Análise de conteúdo. São Paulo: Edições 70, 2016; 279p.

5. BORDIGNON SS, et al. Participação paterna e reação familiar frente a gravidez na adolescência. Revista de Enfermagem UFPE, 2013; 7(6):4456-4465.

6. BRAGA LP, et al. O conceito de paternidade dos adolescentes da rede pública de ensino de Natal/RN. Revista Humano Ser - UNIFACEX, 2015;74-87.

7. BRASIL. Ministério da Saúde. Conselho Nacional de Saúde. Resolução n466 /12. Diretrizes e normas regulamentadoras de pesquisas envolvendo seres humanos. Diário Oficial da República Federativa do Brasil. Brasília, 2012.

8. CRESWELL, J.W. Research design: Qualitative, quantitative, and mixed methods approaches. Sagepublications, 2013; 288p.

9. DIAS ACG, et al. Paternidade Adolescente: Um Estudo sobre Autopercepções do Fenômeno. Revista Psicologia em Pesquisa, 2017; 7(2):230-241.

10. DAVIM BRM, DAVIM CMV. Estudo reflexivo sobre aspectos biológicos, psicossociais e atendimento pré-natal durante a gravidez na adolescência. Revista de Enfermagem UEPE. 2016, 10(8):3108-18, 2016.

11. DIAS ACG. PATIAS NP. Opiniões sobre maternidade em adolescentes grávidas e não-grávidas. Arquivos Brasileiros de Psicologia, 2013; 65(1):88-102.

12. DIAS ACG, et al. O significado da maternidade na adolescência para jovens Gestantes. Revista Brasileira de História \& Ciências Sociais; 2011, 3(6):153-163.

13. DUARTE JVC. Gravidez na Adolescência. [monografia]. Rondon: Universidade Federal do Paraná;2011.

14. EDUARDO KGT, et al. Reações da adolescente frente à gravidez. Escola Anna Nery Revista de EnfermagemUniversidade Federal do Rio de Janeiro, 2005; 9(2):2013-2020.

15. GUEDES JS. Percepção das adolescentes frente ao desafio de ser mãe. 2015. 46f. Trabalho de Conclusão de Curso (Curso de Enfermagem) - Universidade de Brasília, Faculdade de Ceilândia, Ceilândia, Brasília, 2015.

16. Instituto Brasileiro de Geografia e Estatística (IBGE). Síntese de indicadores sociais: uma análise das condições de vida da população brasileira. Rio de Janeiro: IBGE; 2014.

17. Ministério da Saúde (BR). Departamento de Informática Sistema Único de Saúde. MS/SVS/DASIS - Sistema de Informações sobre Nascidos Vivos- SINASC. [Internet]. 2018 [acesso em 2019 mar 06]. Disponível em: http://tabnet.datasus.gov.br/cgi/tabcgi.exe?sinasc/cnv/nvuf.def

18. MIURA OP, TARDIVO LSLPC, BARRIENTOS MSB.O desamparo vivenciado por mães adolescentes e adolescentes grávidas acolhidas institucionalmente. 2018. Revista Ciência \& Saúde Coletiva, 201823(5):16011610.

19. MOREIRA IC. O significado da gravidez para as adolescentes de comunidade de baixa renda. MG, 2010. 
20. MOREIRA TMM, et al. Conflitos vivenciados pelas adolescentes com a descoberta da gravidez. Revista da Escola de Enfermagem da USP, 2008; 42(2):312-20, 2008.

21. NASCIMENTO GM, et al. Adolescentes grávidas: a vivência no âmbito familiar e social. Revista Adolescência e Saúde, Rio de Janeiro. 2011, 8(4):41-47.

22. PAES B, ABRAÃO JLF. Adolescentes gestantes: um olhar para os sentimentos gerados nesta vivência. Colloquium Humanarum, 2014; 11:1182-1188.

23. QUEIROZ MVO, et al. Grupo de gestantes adolescentes: contribuições para o cuidado no pré-natal. Revista Gaúcha de Enferm, 2016; 37(esp):2016-0029.

24. RIBEIRO VCDS, et al. Papel do enfermeiro da estratégia de saúde da família na prevenção da gravidez na adolescência. Revista de Enfermagem do Centro Oeste Mineiro. 2016, 1(1):1957-1975.

25. RODRIGUES FRDA, et al. Ser mãe adolescente: representações de puérperas adolescentes a partir da técnica do desenho-estória. Cogitare Enfermagem, 2009; 14(3,):455-462.

26. SANTOS BPF, MEDEIROS RER. Significados da Maternidade/paternidade para adolescente que vivenciam esse processo. Revista de Enfermagem do Centro Oeste Mineiro, 2015; 5(2):1629-1642.

27. SANTOS CC, et al. Perfil social de adolescentes gestantes e abandono escolar. Revista Adolescência e Saúde, $2014 ; 11(3): 71-76$.

28. SANTOS CC, et al. A vivência da gravidez na adolescência no âmbito familiar e social. Revista de Enferm UFSM, $2014 ; 4(1): 105-112$.

29. SANTOS NLB, GUIMARAES DA, GAMA CAP. A percepção de mães adolescentes sobre seu processo de gravidez. Revista Psicologia e Saúde, 2016; 8 (2): 83-96.

30. SILVA MHD. Paternidade na adolescência: expectativas e sentimentos frente a essa realidade. Revista de Enferm UFPE on line, 2016; 10(1): 309-15.

31. SOARES PDF. Reincidência da Gravidez na Adolescência: Percepções das Adolescentes. Enfermagem em Foco, 2016; 7(3):66-70.

32. TABORDA, JA, et al. Consequências da gravidez na adolescência para as meninas considerando-se a diferenças socioeconômicas entre elas. Caddernos de Saúde Coletiva, 2014; 22(1): 16-24.

33. VASCONCELOS JLDGP, et al. ser mãe adolescente: representações de puérperas adolescentes a partir da técnica do desenho-estória. Revista Cogitare Enferm, 2009 14(3): 455-62.

34. YIN RK. Estudo de caso: planejamento e métodos. 5. ed. Bookman. 2016; 270p. 